\title{
Maternal Depression, Parental Practices and Child Sex: Prediction of Children's Behavior
}

\author{
Marianna Ramos e Oliveira ${ }^{1}$ \\ Thaysa Brinck Fernandes Silva ${ }^{1}$ (D) \\ Fernanda Aguiar Pizeta² (iD \\ Sonia Regina Loureiro ${ }^{1}$
}

\begin{abstract}
Exposure to maternal depressive symptoms and negative parenting practices during childhood configures a vulnerability factor associated with behavior problems among children. This study aims to verify the predictive effects of maternal depression (main factor) on behavioral outcomes and maternal parenting practices, considering the sex of the children (covariate factor); and the predictive effect of maternal depression, parenting practices, and child's sex on behavioral outcomes. The sample was composed of a community sample of 101 mother-child pairs. Mothers answered to: Structured Clinical Interview for DSM Disorders, Parenting Styles Inventory, and Strengths and Difficulties Questionnaire. The covariance and multiple linear regressions analysis showed that being a boy, and specific practices of neglect, physical abuse, and permissive discipline were the main predictors of behavioral problems among children exposed to negative practices and maternal depression. These findings underline the role of the child's sex in the interactions between variables, which could contribute to interventions in mental health.
\end{abstract}

Keywords: depression, early childhood education, sex, child psychology

\section{Depressão Materna, Práticas Parentais e Sexo das Crianças: Predição de Comportamentos Infantis}

\begin{abstract}
Resumo: Na infância, a exposição a sintomas depressivos maternos e práticas parentais negativas configura-se como vulnerabilidade, associando-se a problemas comportamentais. Este estudo teve por objetivos: verificar o efeito da depressão materna (fator principal) para os indicadores comportamentais e práticas parentais, considerando-se o efeito do sexo dos filhos (fator covariável); e verificar os efeitos preditivos da depressão materna, práticas parentais maternas e sexo das crianças para os indicadores comportamentais. Incluída amostra da comunidade de 101 díades de mães-crianças. As mães responderam: Entrevista Clínica Estruturada para o DSM-IV, Inventário de Estilos Parentais e Questionário de Capacidades e Dificuldades da Criança. Análises de covariância e regressão linear multivariada evidenciaram o sexo masculino e práticas de negligência, abuso físico e disciplina relaxada como principais preditores de problemas comportamentais de crianças expostas a práticas negativas e depressão materna. Tais resultados evidenciam o papel do sexo nas interações entre as variáveis, podendo nortear intervenções em saúde-mental.
\end{abstract}

Palavras-chave: depressão, educação infantil, sexo, psicologia da criança

\section{Depresión Materna, Prácticas Parentales y Sexo de los Niños: Predicción de Comportamientos Infantiles}

\begin{abstract}
Resumen: La exposición a depresión materna y prácticas parentales negativas en la infancia se configuran como factor de vulnerabilidad relacionado con problemas comportamentales. Este estudio tuvo por objetivo verificar el efecto de la depresión materna (factor principal) en los indicadores comportamentales y prácticas parentales, considerando el efecto del sexo de los hijos (factor covariable); así como identificar los efectos predictivos de la depresión, las prácticas parentales maternas y el sexo de los niños en los indicadores comportamentales. Se compuso la muestra comunitaria con 101 díadas madres-hijos. Las madres respondieron a la Entrevista Clínica Estructurada para el DSM-IV, al Inventario de Estilos Parentales y al Cuestionario de Capacidades y Dificultades. Los análisis de covariancia y de regresión lineal multivariada evidenciaron el sexo masculino y las prácticas de negligencia, abuso físico y disciplina relajada como los principales predictores de problemas comportamentales de niños expuestos a prácticas negativas y a depresión materna. Tales resultados evidencian el papel del sexo en las interacciones entre las variables, favoreciendo las intervenciones en salud mental.
\end{abstract}

Palabras clave: depresión, crianza del niño, sexo, psicología infantil

${ }^{1}$ Universidade de São Paulo, Ribeirão Preto-SP, Brazil

${ }^{2}$ Universidade Paulista, Ribeirão Preto-SP, Brazil

This article derived from the first author's master's thesis under supervision of the fourth, defended in 2020, in the Graduate Program in Mental Health of the Faculdade de Medicina de Ribeirão Preto of Universidade de São Paulo. Support: Funding: CNPq/307945/2018 and CAPES, Financing Code 001.

Correspondence address: Marianna Ramos e Oliveira. Universidade de São Paulo. Rua Tenente Catão Roxo, 2650, Ribeirão Preto-SP, Brazil. CEP 14.040-900. E-mail: ramosmarianna.oliveira@gmail.com
Childhood is a critical period for determining the mental health, relationships, and emotional capacity of the individual throughout life (Orth, 2018). More specifically, the third childhood (six to 11 years of age) is a moment of greater specialization of cognitive and social acquisitions, with new learning experiences with peers, school, and family (Papalia \& Feldman, 2013). In this phase, behavior is a valuable indicator of development, expressing prosocial 
capacities and resources, but also difficulties and problems of adaptation, conduct, and relationships.

Among the elements that can influence the outcomes of child development, we highlight the configuration of the family as a dynamic condition of adversity if negative interactions between parents and children (González-Cámara, Osorio, \& Reparaz, 2019), and/or mental health problems of parents, such as maternal depression, occur (Charrois et al., 2020; S.H. Goodman et al., 2011; Schiavo \& Perosa, 2020).

Depressive disorders manifest as depressed mood; sadness; loss of interest and energy; sleep and appetite disorders; somatic complaints; and difficulty in concentration, with variations in duration, frequency, and intensity of manifestations (American Psychiatric Association [APA], 2014). In Brazil, major depressive disorder mainly affects adult women living in urban areas (Lopes, Hellwig, Silva, \& Menezes, 2016), many of whom are of childbearing age and/or are mothers. Thus, living with depressive symptoms in the family environment can be considered a condition of adversity for children, as indicated by the systematic review by Vafaeenejad, Elyasi, Moosazadeh, and Shahhosseini (2018), which found that the mental health of parents is one of the main factors affecting family interactions and the childcare condition, making clear the presence of competing adverse variables for child development.

Regarding family relationships, maternal parental practices make up a continuum of complex behaviors and may have different effects on the children. Generally, two sets of practices stand out, those considered positive for favoring the development of the children and functioning as protection mechanisms, including practices of affection (displays of affection, appreciation, and praise), sensitivity (interest and responsiveness to the child's needs), and positive discipline (monitoring) (Bödeker et al., 2019); and those considered negative because they associate with more problems and fewer resources for the children, including psychological aggression (screaming, threatening, and swearing) (Kuckertz, Mitchell, \& Wiggins, 2018), physical and psychological abuse (Wolford, Cooper, \& McWey, 2019), and authoritarianism (Calzada, Sales, \& O'Garaa, 2019). Concerning depression, mothers have been considered more aggressive (Kuckertz et al., 2018) and less sensitive (Bödeker et al., 2019), and the maternal depressive symptomatology affects negatively on the children's behavior (S.H. Goodman et al., 2011).

Another notable variable in the literature on child behavior is the sex of the child, with several studies indicating that maternal depressive symptoms and parental practices seem to exert different effects for boys and girls (Assis-Fernandes \& Bolsoni-Silva, 2020; Nantel-Vivier, Pihl, Côté, \& Tremblay, 2014; Wang, 2018).We will describe empirical studies that evaluated parental practices and the behavior of boys and girls and their diverse results in order to contextualize this question.

The longitudinal study by Hosokawa and Katsura (2019) found an association between authoritarian parenting styles and more externalizing behavior problems for schoolchildren of both sexes, and of permissive parental practices with externalizing problems only for girls, indicating a higher risk associated with females. The study by Zubizarreta, Calvete and Hankin (2019), showed significant effects of punitive parenting styles for both sexes, but for boys the punishment was a predictor of more depressive symptoms, indicating a higher risk associated with males.

Regarding the differences between the forms of care employed, the systematic review by Endendijk, Groeneveld, Bakermans-Kranenburg and Mesman (2016) found that mothers seem to exercise more practices of control with boys and more practices of favoring autonomy with girls. This shows differentiated aspects of maternal care for sons and daughters, which may also be affected by other variables of the family environment.

Concerning exposure to maternal depression, Wang (2018) found that maternal negative parental practices were predictors of depressive (internalizing) symptoms only for boys. Regarding externalizing outcomes, the longitudinal study by Shaw, Sitnick, Reuben, Dishion and Wilson (2016) found that depressive symptoms and maternal negative parental practices were significant predictors of more conduct problems for all children, with no significant differences identified between sexes.

Regarding the positive development of resources, the study by Nantel-Vivier et al. (2014) found that boys had increased risk of low development of prosocial skills, regardless of maternal depressive practices and symptoms. With similar results, Castelao and Kroner-Herwig (2014) found that being a boy, exposed to depressive symptoms and negative maternal practices, was a predictor of the increased risk for behavior problems, while being a girl was identified as a protective factor.

Analyzing the set of reported studies that addressed behavioral differences between boys and girls and associations with parental practices and maternal depression, the results regarding greater vulnerability for girls or boys, and the differences in practices adopted by mothers with depression were inconclusive.

Considering that maternal depression affects parental practices (Wolford et al., 2019) and children's behavior (S.H. Goodman et al., 2011), the focus of this studyaiming to investigate the associations of maternal parental practices with the behaviors of boys and girls in the context of maternal depression, contributing to elucidate the possible mechanisms that favor or impair child behavioral outcomes - is justified. The role of maternal depression in explanatory models for behavioral outcomes of sons and daughters exposed to it is still undetermined and exploring models that favor the understanding of the relationships between these variables is relevant.

To investigate the aforementioned factors, this study aimed to verify the effect of maternal depression (main factor) for behavioral indicators and parental practices, considering the effect of the children's sex (covariate factor); and to verify the predictive effects of maternal 
depression, maternal parenting practices and children's gender for behavioral indicators. Considering previous studies, we formulated the following hypotheses: (a) maternal depression will be associated with more behavior problems and more negative parental practices, with a differentiated impact for boys and girls; and (b) specific parental practices, especially negative ones, will be predictors of more behavior problems in the presence of maternal depression and the sex of children, and different practices can be identified for different behavior problems.

\section{Method}

\section{Participants}

With a cross-sectional, correlational, and predictive design, a convenience community sample of 101 motherchild dyad was included. The mothers were systematically evaluated by the Diagnostic Interview for the DSM-IV SCID; 51 met the diagnostic criteria for Major Depressive Disorder and 50 did not meet these criteria.

The participating women/mothers were aged from 31 to 55 years, with a mean age of 37.2 years $(S D=6.419)$. Most women had more than eight years of schooling (79.2\%), paid work $(68.3 \%)$, and were married or in a stable union (72.3\%). Most of the sample belonged to a median family socioeconomic level $(73.3 \%)$, according to the Brazilian Institute of Geography and Statistics (IBGE) socioeconomic classification. The children, 51 boys and 50 girls, were age from eight to 11 years, mean age of 9.5 years $(S D=1.083)$, attending school grade compatible with their age.

The inclusion criteria adopted were the minimum age of 25 years for women/mothers and eight years for children, an age group in which they were considered already adapted to formal education. To prevent biases and confounding variables, children with apparent disabilities and/or chronic diseases reported by the mothers; those who did not live with their biological family; and those with an intellectual level below average, according to Raven's Colored Progressive Matrices Test, were not included. Only one child per family was included, and in cases where more than one eligible child was present, the criterion of choice for inclusion in the study was gender, favoring the balancing of this variable.

\section{Instruments}

The indicators of child behavior, an outcome considered in the study, were reported by the mothers through the Strengths and Difficulties Questionnaire $S D Q$, developed by R. Goodman (1997) and translated into and adapted for the Portuguese by Fleitlich and Goodman (2001), with satisfactory psychometric properties measured (Woerner et al., 2004). The questionnaire consists of
25 items, divided into five scales: four assessing problem indicators (Emotional Symptoms, Conduct Problems, Hyperactivity, and Peer Relationship), and one assessing resource indicators (Prosocial Behavior). According to A. Goodman, Lamping and Ploubidis (2010), in a study on factorial structure, these scales are grouped into three factors: internalization problems (10 items, emotional and relationships), externalization problems (10 items, hyperactivity and conduct), and prosocial behaviors (5 items), the use of these scores being recommended with community and low risk samples. Altafim, McCoy and Linhares (2018) confirmed this structure in Brazil. In our study, data from the total score of difficulties and the five specific scales, based on the assumption of exposure to multiple risks, namely: maternal depression and negative parental practices. The reliability analysis for this sample resulted in a Cronbach's Alpha of 0.84 .

Maternal depressive indicators, a condition for inclusion in the groups, were obtained by the Structured Clinical Interview for the DSM-IV - SCID-IV (Mood Disorders Module), which is a clinical interview organized in modules that correspond to the main diagnostic categories of mental disorders, evaluated for the duration, frequency, and intensity of current and previous manifestations. It is considered the gold standard for such evaluation, with translation into and adaptation for Brazilian Portuguese (Del-Ben et al., 2001). In our study, professionals with clinical experience conducted the application and evaluation of the test, and the diagnosis of mothers with depression was used as a categorical variable in statistical analyses: depression, when mothers were diagnosed with major depressive disorder, current or past; or not depression, when mothers did not present current or past depressive indicators. The SCID-IV version used includes all the diagnostic criteria established for the DSM5 (APA, 2014) concerning depressive disorders.

Parental practices were evaluated by the mother's answers to the Parental Styles Inventory - PSI, which was developed and validated by Gomide (2006). It has 42 items and derives from a theoretical model composed of seven educational practices, two positive (positive monitoring and moral behavior) and five negative (physical abuse, relaxed discipline, negative monitoring, neglect, and inconsistent punishment). In our study, we used the total scores of positive practices and negative practices, and the scores of each of the seven specific parental practices. The reliability analysis of this instrument for this sample resulted in a Cronbach's Alpha of 0.71 .

The sex of the children variable (male and female) was obtained by the mothers' response to a general questionnaire on sociodemographic data of the families, mothers, and children.

Bias control: the children's intellectual level was included as a selection/exclusion criterion, which was decided beforehand, based on analysis of the literature, so that the behavior outcomes did not suffer the effect of possible intellectual difficulties. Raven's Colored Progressive 
Matrices Test - Special Scale (Angelini, Alves, Custódio, Duarte, \& Duarte, 1999) - a nonverbal intelligence test that assesses the general intellectual capacity of children aged five to 11 years, with Brazilian standardization, good psychometric properties, and satisfactory ability to assess cognitive level by using factor analysis (Muniz, Gomes, \& Pasian, 2016) - was applied. An intellectual performance corresponding to the percentile greater than or equal to 25 was adopted as inclusion criteria for this study.

\section{Procedure}

Data collection. The participants were recruited by contact with children from four public elementary schools in a medium-sized city in the state of Minas Gerais, Brazil, between 2016 and 2017. Among the four schools contacted there were a total of 1,756 eligible children, considered as the intended population. A sample calculation of this population was performed, with a $10 \%$ margin of error and a $95 \%$ confidence interval, reaching the ideal sample of 92 participants (ranging from 82 to 102).

Invitations were distributed to all children, out of which 290 returned with the acceptance for participation. Among these, 180 were excluded due to lack of availability, age of children outside the criteria, and children who did not live with their families of origin. Then, 110 motherchild dyads were evaluated, nine of which were excluded due to incomplete evaluation (five participants) or child's intellectual level below the established criterion. In faceto-face, individual sessions, the mothers responded to the instruments in a single meeting, in the following order: General questionnaire, SCID, PSI, and SDQ. After the evaluation with the mothers, the children responded to Raven's test.

Data analysis. Descriptive statistical analyses were conducted, with calculation of frequency and percentage for categorical variables, and mean and standard deviation for continuous variables. Normality and homogeneity of variance tests were performed for decision-making regarding prediction analyses and the quality of the tested models (Marôco, 2014).

To meet the first objective of the study, two models of covariance analyses (ANCOVA) were conducted in order to understand the effect of the sex variable (covariate factor), in the presence of maternal depression (main factor), for child behavior problems and for specific parental practices. Thus, the first model was tested for total difficulties and for each scale of the SDQ, and the second model was tested for the PSI indicators, to verify the differentiated explanatory power of maternal depressive symptoms and sex of the children for behavior and parental practices, respectively. To verify the validity of the analyses by ANCOVA, normality and homogeneity of variance tests were performed. Among the variables tested, negligence violated the assumptions of homogeneity and was later excluded.
To meet the second objective of the study, multivariate linear regression models were conducted to predict children's behavior - including as independent variables the presence of maternal depression (categorical variable), negative parental practices (continuous variable), and the sex of the children (boy and girl) — as a complementary resource to understand the direct effect of each variable in the presence of the other variables in a model in which the different variables occupy competing places of prediction. Multicollinearity was verified by calculating variance inflation factor (VIF), and none of the variables included in the prediction models exceeded limit values greater than three, being considered as independent variables. Different models were tested for total difficulties and for each SDQ scale, considering the presence or absence of maternal depression (in all models) and specific parental practices for each outcome, thus varying the inclusion of practices in each model tested for the SDQ scales. For the choice of inclusion in the final model regarding the predictor variables related to specific maternal parental practices, previous analyses of univariate regression were performed and only the practices identified with statistical significance for the behavioral outcomes of the children were included.

\section{Ethical Considerations}

This study was approved by a Research Ethics Committee of the Universidade Federal do Triângulo Mineiro (CAAE No. 42693514.1.0000.5154). A consent form for data collection was presented for the schools, sources of the participants, which the principals signed. The mothers signed an informed consent form, and consent was obtained for the children's participation in the study by signing the informed assent form. Reception and guidance were offered for all diagnosed participants on the identification of depressive symptoms, and referrals were made to mothers and children to the mental health network when necessary.

\section{Results}

Table 1 shows model 1 of covariance analyses (ANCOVA), in which the effects of maternal depression (main factor) for behavior (outcome) measured by the SDQ were tested, controlling the effects of children's sex (covariate).

Maternal depressive symptoms significantly affected the increase in emotional symptoms after controlling the sex of the children. Regarding total behavioral difficulties and behavior problems, peer relationships, hyperactivity and prosocial behavior, maternal depression showed no significant effect when controlling the sex of the children. Sex, in turn, proved significant for more behavior problems in total, conduct and peer relationship problems for boys and for more prosocial behavior resources for girls. 
Table 1

Covariance analyses (ANCOVA) for the prediction of behavior outcomes (total and scales), considering maternal depression and the sex of the children

\begin{tabular}{|c|c|c|c|c|c|}
\hline Source & Dependent Variable & SQ & MQ & $F$ & $p$-value \\
\hline Maternal Depression & Total Difficulties & 142.788 & 142.788 & 3.516 & 0.064 \\
\hline Child Sex - Boys & & 432.326 & 432.326 & 10.645 & $0.002 *$ \\
\hline Maternal Depression & Emotional Symptoms & 43.214 & 43.214 & 7.351 & $0.008^{*}$ \\
\hline Child Sex - Boys & & 17.322 & 17.322 & 2.947 & 0.089 \\
\hline Maternal Depression & Conduct Problems & 5.473 & 5.473 & 1.420 & 0.236 \\
\hline Child Sex - Boys & & 26.556 & 26.556 & 6.890 & $0.010^{*}$ \\
\hline Maternal Depression & Hyperactivity & 3.953 & 3.953 & 0.421 & 0.518 \\
\hline Child Sex - Boys & & 29.213 & 29.213 & 3.112 & 0.081 \\
\hline Maternal Depression & Peer Relationship Problems & 1.564 & 1.564 & 0.510 & 0.477 \\
\hline Child Sex - Boys & & 34.495 & 34.495 & 11.247 & $0.001^{*}$ \\
\hline Maternal Depression & Prosocial Behavior & 1.855 & 1.855 & 0.706 & 0.403 \\
\hline Child Sex - Girls & & 15.798 & 15.798 & 6.010 & $0.016^{*}$ \\
\hline
\end{tabular}

Note. $* p<0.05 ; \mathrm{SQ}=$ sum of squares; $\mathrm{MQ}=$ mean square; $\mathrm{F}=$ test value.

Table 2 shows model 2 of covariance analyses (ANCOVA), with the effect of maternal depression (main factor) for maternal parental practices (total outcome and scales), controlling the sex of the children (covariate factor).

For the total maternal negative parental practices and for the specific practices of inconsistent punishment and relaxed discipline, maternal depression had a significant effect after controlling the effect of the children's sex. Regarding total positive practices, positive and negative monitoring, moral behavior, and physical abuse, maternal depression had no significant effect after controlling the children's sex. For negative monitoring, the male gender was configured as an effect variable.

Table 2

Covariance analyses (ANCOVA) for the prediction of maternal parental practices (total and scales), considering maternal depression and the sex of the children

\begin{tabular}{|c|c|c|c|c|c|}
\hline Source & Dependent Variable & SQ & MQ & $F$ & p-value \\
\hline Maternal Depression & Total Positive Practices & 0.347 & 0.347 & 0.069 & 0.793 \\
\hline Child Sex - Boys & & 0.625 & 0.625 & 0.124 & 0.725 \\
\hline Maternal Depression & Total Negative Practices & 447.550 & 447.550 & 9.146 & $0.003 *$ \\
\hline Child Sex - Boys & & 12.036 & 12.036 & 0.246 & 0.621 \\
\hline Maternal Depression & Positive Monitoring & 4.416 & 4.416 & 2.749 & 0.101 \\
\hline Child Sex - Girls & & 0.244 & 0.244 & 0.152 & 0.698 \\
\hline Maternal Depression & Moral Behavior & 2.287 & 2.287 & 1.206 & 0.275 \\
\hline Child Sex - Girls & & 0.088 & 0.088 & 0.046 & 0.830 \\
\hline Maternal Depression & Inconsistent Punishment & 27.366 & 27.366 & 4.952 & $0.028^{*}$ \\
\hline Child Sex - Boys & & 0.357 & 0.357 & 0.065 & 0.800 \\
\hline Maternal Depression & Relaxed Discipline & 33.652 & 33.652 & 6.524 & $0.012 *$ \\
\hline Child Sex - Boys & & 6.970 & 6.970 & 1.351 & 0.248 \\
\hline Maternal Depression & Negative Monitoring & 0.227 & 0.227 & 0.058 & 0.810 \\
\hline Child Sex - Boys & & 16.758 & 16.758 & 4.317 & $0.040^{*}$ \\
\hline Maternal Depression & Physical Abuse & 4.016 & 4.016 & 1.018 & 0.315 \\
\hline Child Sex - Boys & & 4.016 & 4.016 & 1.018 & 0.315 \\
\hline
\end{tabular}

Note. ${ }^{*} p<0.05 ; \mathrm{SQ}=$ sum of squares; $\mathrm{MQ}=$ mean square; $\mathrm{F}=$ test value. 
Table 3 shows the results of multivariate linear regression. Maternal depression (considered as the presence or absence of diagnosis), negative parental practices (which presented significance for behavior problems in the univariate analysis), and the sex of the children were considered as independent variables.

For the total behavioral difficulties, the child's sex (male), neglect, physical abuse, and relaxed discipline were predictors of more problems, being responsible for about $45 \%$ of the score variation. Regarding emotional symptoms and hyperactivity, neglect was the only predictor, accounting for $14 \%$ and $16 \%$ of the score variation, respectively. Regarding conduct problems, the predictor variables were male gender, neglect, and physical abuse, causing about $33 \%$ of variance. And for peer relationship problems, the predictor variables were male gender, neglect, physical abuse, and relaxed discipline, causing about $30 \%$ of variance. Contrary to expectations, maternal depression was not identified as a predictor for any of the outcomes.

Table 3

Multiple linear regression analysis considering the predictor variables of children's behavioral problems $(n=101)$

\begin{tabular}{|c|c|c|c|c|c|c|c|}
\hline Predictive Characteristic & Outcomes & $\beta$ & $t$ & p-value & $95 \% \mathrm{CI}^{*}$ & VIF & $\begin{array}{c}\text { Total } \\
\text { adjusted } R^{2} \\
\end{array}$ \\
\hline Child Sex - Boys & Total Difficulties & -0.279 & -3.695 & $0.000 *$ & $-5.754 ;-1.732$ & 1.029 & 0.448 \\
\hline Negligence & & 0.428 & 4.920 & $0.000^{*}$ & $0.842 ; 1.1981$ & 1.370 & \\
\hline Physical Abuse & & 0.203 & 2.471 & $0.015^{*}$ & $0.135 ; 1.243$ & 1.219 & \\
\hline Relaxed Discipline & & 0.258 & 3.280 & $0.001 *$ & $0.294 ; 1.195$ & 1.118 & \\
\hline Negligence & Emotional Symptoms & 0.281 & 2.855 & $0.005^{*}$ & $0.106 ; 0.588$ & 1.129 & 0.140 \\
\hline Child Sex - Boys & Conduct Problems & -0.194 & -2.355 & $0.021 *$ & $-1.441 ; 0.123$ & 1.014 & \\
\hline Negligence & & 0.426 & 4.515 & $0.000^{*}$ & $0.236 ; 0.606$ & 1.327 & 0.331 \\
\hline Physical Abuse & & 0.225 & 2.505 & $0.014 *$ & $0.047 ; 0.410$ & 1.201 & \\
\hline Negligence & Hyperactivity & 0.343 & 3.281 & $0.001 *$ & $0.204 ; 0.830$ & 1.296 & 0.158 \\
\hline Child Sex - Boys & Peer Relationship & -0.306 & -3.593 & $0.001 *$ & $-1.733 ;-0.499$ & 1.029 & 0.298 \\
\hline Negligence & Problems & 0.275 & 2.799 & $0.006^{*}$ & $0.072 ; 0.421$ & 1.370 & \\
\hline Physical Abuse & & 0.201 & 2.175 & $0.032 *$ & $0.016 ; 0.356$ & 1.219 & \\
\hline Relaxed Discipline & & 0.268 & 3.019 & $0.003 *$ & $0.072 ; 0.348$ & 1.118 & \\
\hline
\end{tabular}

Note. ${ }^{*} p<0.05 ; \beta=$ beta coefficient; $t=\mathrm{t}$-test value; $95 \% \mathrm{CI}=95 \%$ confidence interval; $\mathrm{VIF}=$ variance inflation factor.

\section{Discussion}

Considering the proposed objectives, the findings of our study demonstrate the significant and distinct impact of maternal depression, negative parental practices, and male sex for the presence of behavioral problems of children, composing different explanatory models for each outcome. Note that: (a) maternal depression was associated with more negative practices, but was not a predictor of the set of behavior problems of children, limiting itself to the prediction of emotional symptoms; and (b) being a boy was a significant condition for some outcomes of behavior problems, while being a girl was associated with the presence of more socialization resources in the presence of maternal depression and negative parental practices, which evidenced the relevance of children's sex as a covariate in the models and as a competing variable in the multivariate regression models. The findings allowed us to corroborate the two hypotheses formulated for the study; the association of maternal depression with more negative practices was entirely corroborated, and the association with more emotional symptoms of children was partially corroborated. We also verified the differentiated effect of children's sex in the presence of maternal depression and specific practices, separately, independently (ANCOVAS) and in combination (regression analyses).

Regarding the impact of maternal depression on the presence of more emotional symptoms of children, we note some agreement with other studies, which also identified emotional symptoms in schoolchildren living with mothers with depression (Calzada et al., 2019; Kuckertz et al., 2018). These indicators seem to reiterate a result widely discussed in the literature regarding a transgenerational model of reciprocal influences between maternal internalizing symptoms and the internalizing symptoms of children (Kuckertz et al., 2018). In this study, the internalizing symptoms of children can be thought to reflect an expressiveness learned in the interaction with mothers (S.H. Goodman et al., 2011); however, without losing sight of the genetic hypothesis related to depression, not addressed by the study.

Regarding the effects on parental practices, covariance analyses showed that maternal depression had predictive value for the presence of more negative practices when the effects of the sex of the children were controlled, and for 
relaxed discipline and inconsistent punishment practices. These findings corroborate a review on parenting styles, which indicates that the mother's mental health status is a significant risk factor for the increase in negative behaviors in relation to children (Vafaeenejad et al., 2018). These results also draw attention to the presence of multiple adverse variables of the family context that, combined, impact child development.

The negative practices relaxed discipline and inconsistent punishment may be related to typical manifestations of mood instability of depressive symptomatology, characterizing attitudes of permissiveness and inconsistency that are related to the mother's little involvement. Our study aligns with the findings of Bödeker et al. (2019), who identified that maternal depressive symptoms impaired the sensitivity and attention of mothers to their children, and with the statements of Charrois et al. (2020) regarding the negative interference of depression in the confidence of mothers in their ability to care for their children, favoring the removal from family routine and the abstention from offering support and affection necessary for the adaptive development of children.

Also, regarding covariance analyses, male children were exposed to more negative practices, being the only variable affecting the reporting of more negative monitoring by mothers. This corroborates Endendijk et al.'s (2016) metaanalysis results that parents were more controlling with boys, and more promoters of autonomy and freedom for girls.

Our data agrees with the hypothesis of DetteHagenmeyer and Reichle (2014), that mothers seem to feel more need to keep an eye on boys, since they consider that boys are more exposed to risks and vulnerability. However, despite the controlling purpose, the most authoritarian forms of discipline disregard the particularities of children in interactions and are imposing, which may lead to the children's difficulty in regulating their behaviors, increasing the risk for externalizing problems (Hosokawa \& Katsura, 2019). This statement seems pertinent to the results of this sample, in which the boys presented more indicators of behavioral problems, data that will be discussed below.

In the covariance analyses, being a boy was associated with more problems in the total difficulties among the children, in addition to more problems of conduct and peer relationship. These findings confirm the initial hypotheses of our study regarding the differences between the sexes regarding the indicators of behavioral difficulties, and other studies (Wang, 2018; Zubizarreta et al., 2019) also identified greater risks for problems for boys. The girls, on the other hand, were associated with more resources of Prosocial Behavior, which agrees with the findings of the study by Nantel-Vivier et al. (2014). These results suggest that, in the present sample, exposure to adverse conditions related to maternal depression and negative practices had a greater impact on the behavior of boys.

Regarding the prediction of children's behavioral problems, neglect stood out as only variable that presented significant predictive value in all analyses in which it was included. This data can be interpreted in the light of the results of a systematic review, which reported that parental practices of mistreatment, aggression and neglect were among the most important conditions of adversity and risk identified for children, which may lead to atypical outcomes, dysfunctional relationship patterns and poor school adaptation (Cicchetti \& Handley, 2019). Furthermore, factors considered protective for a good behavioral, emotional and self-esteem development of the child highlight the quality of the family environment, attentive presence and parental stimulation, emphasizing the importance of the absence of negligent and aggressive behaviors (Orth, 2018).

Another negative practice highlighted was physical abuse, a predictor of more problems in general and more conduct and peer relationship problems. Our study corroborates the findings of Cui, Deatrick and Liu (2018) and Wolford et al. (2019), who found that the use of physical abuse practices by parents, especially by mothers, was associated with multiple children problems. The use of physical force as a form of control act as a model of aggressive behavior that mothers offer children that can be learned and later reproduced by them in interactions with family and peers.

We point out that the parental practices evidenced in the multivariate regression model - when analyzed by their more objective aspects of actions, such as omission of care, aggressions, physical punishment, permissiveness and non-imposition of limits - can be learned in preventive/ interventional programs, if they are associated with more specific mental health care, which also contemplate the dimension of affections and mood of mothers, through the treatment of depression. Thus, the results identified in a sample of the community of mothers with clinical indicators of depression show the importance of the dissemination of mental health care and intervention programs beyond the scientific community and unrestricted to mothers of samples recognized as clinics. Actions aimed at the general population and disseminated in important environments to childcare, such as schools, can greatly benefit both mothers and children.

Our study responds to the proposed objectives and advances knowledge; however, it presents methodological limits. The mothers were the only informants about parental practices, depressive symptoms and children's behavior; and the design was cross-sectional, which limited the observation of the temporal continuity of the variables studied. Caution is recommended regarding the generalization of the identified results, and further research is needed to expand the methodological scope of the study, considering the sociocultural specificities of each sample.

On the other hand, we highlight the methodological care adopted that contributed to the quality of the study, namely: the systematic evaluation of depression by using a gold standard diagnostic interview conducted by trained evaluators with clinical experience; the inclusion of the evaluation of positive and negative parental practices, which favored knowledge about their differentiated influence; and the exclusion of children with some intellectual limitation, according to systematic evaluation of the cognitive level, so that behavioral indicators were free from the influence of this bias.

We consider the advances in the recognition of the variables associated with child behavior in the context of 
maternal depression - with emphasis on negative practices, especially neglect and physical abuse - and with males in predicting children's problems as the main contribution of this study. Furthermore, when addressing the sex of the children as an independent variable, the study advances regarding the peculiarities of maternal practices for boys and girls, and shows that males in the sample studied constituted an important risk factor. Thus, the relevance of children's sex in the interactions between the variables maternal depression and negative practices is evidenced, which can guide new studies and, mainly, more specific interventions in mental health.

\section{References}

Altafim, E. R. P., McCoy, D. C., \& Linhares, M. B. M. (2018). Relations between parenting practices, socioeconomic status, and child behavior in Brazil. Children and Youth Services Review, 89, 93-102. doi:10.1016/ j.childyouth.2018.04.025

American Psychiatric Association. (2014). Manual diagnóstico e estatístico de transtornos mentais: DSM-5 [Diagnostic and statistical manual of mental disorders: DSM-5] (M. I. C. Nascimento, P. H. Machado, R. M. Garcez, R. Pizzato, \& S. M. M. Rosa, Trans., 5th ed.). Porto Alegre, RS: Artmed.

Angelini, A. L., Alves, I. C., Custódio, E. M., Duarte, W. F., \& Duarte, J. L. (1999). Manual das matrizes progressivas coloridas de Raven: Escala especial. [Raven's Colored Progressive Matrices for Children: Special Scale] São Paulo, SP: Centro Editor de Testes e Pesquisas em Psicologia.

Assis-Fernandes, R. P., \& Bolsoni-Silva, A. T. (2020). Educational social skills and repertory of children differentiated by behavior and sex. Paidéia (Ribeirão Preto), 30, e3015. doi:10.1590/1982-4327e3015

Bödeker, K., Fuchs, A., Führer, D., Kluczniok, D., Dittrich, K., Reichl, C., ... Resch, F. (2019). Impact of maternal early life maltreatment and maternal history of depression on child psychopathology: Mediating role of maternal sensitivity? Child Psychiatry \& Human Development, 50(2), 278-290. doi:10.1007/s10578-018-0839-z

Calzada, E. J., Sales, A., \& O'Gara, J. L. (2019). Maternal depression and acculturative stress impacts on Mexicanorigin children through authoritarian parenting. Journal of Applied Developmental Psychology, 63, 65-75. doi:10.1016/j.appdev.2019.05.001

Castelao, C. F., \& Kroner-Herwig, B. (2014). Developmental trajectories and predictors of externalizing behavior: A comparison of girls and boys. Journal of Youth and Adolescence, 43(5), 775-789. doi:10.1007/s10964-013-0011-9

Charrois, J., Côté, S. M., Paquin, S., Séguin, J. R., Japel, C., Vitaro, F., ... Herba, C. M. (2020). Maternal depression in early childhood and child emotional and behavioral outcomes at school age: Examining the roles of preschool childcare quality and current maternal depression symptomatology. European Child \& Adolescent Psychiatry, 29(5), 637-648. doi:10.1007/s00787-019-01385-7
Cicchetti, D., \& Handley, E. D. (2019). Child maltreatment and the development of substance use and disorder. Neurobiology of stress, 10, 100-144. doi:10.1016/ j.ynstr.2018.100144

Cui, N., Deatrick, J. A., \& Liu, J. (2018). Maternal and paternal physical abuse: Unique and joint associations with child behavioral problems. Child Abuse and Neglect, 76, 524-532. doi:10.1016/j.chiabu.2017.05.003

Del-Ben, C. M., Vilela, J. A. A., Crippa, J. A. S., Hallak, J. E.C., Labate, C. M., \& Zuardi, A. W. (2001). Confiabilidade da Entrevista Clínica Estruturada para o DSM-IV - Versão Clínica traduzida para o português [Reliability of the Structured Clinical Interview for DSM-IV - Clinical Version translated into Portuguese]. Revista Brasileira de Psiquiatria, 23(3), 156-159. doi:10.1590/s1516-44462001000300008

Dette-Hagenmeyer, D. E., \& Reichle, B. (2014). Parents' depressive symptoms and children's adjustment over time are mediated by parenting, but differentially for fathers and mothers. European Journal of Developmental Psychology, 11(2), 196-210. doi:10.1080/17405629.2013.848789

Endendijk, J. J., Groeneveld, M. G., Bakermans-Kranenburg, M. J., \& Mesman, J. (2016). Gender-differentiated parenting revisited: Meta-analysis reveals very few differences in parental control of boys and girls. PLoS One, 11(7), e0159193. doi:10.1371/journal.pone.0159193

Fleitlich, B., \& Goodman, R. (2001). Social factors associated with child mental health problems in Brazil: Cross sectional survey. British Medical Journal, 323(7313), 599-600. doi:10.1136/bmj.323.7313.599

Gomide, P. I. C. (2006). Inventários de Estilos Parentais (IEP): Modelo teórico, manual de aplicação, apuração $e$ interpretação [Parenting Styles Inventory (IEP): Theoretical model, application manual, verification and interpretation]. Rio de Janeiro, RJ: Vozes.

González-Cámara, M., Osorio, A., \& Reparaz, C. (2019). Measurement and function of the control dimension in parenting styles: A systematic review. International Journal of Environmental Research and Public Health, 16(17), 3157. doi:10.3390/ijerph16173157

Goodman, A., Lamping, D. L., \& Ploubidis, G. B. (2010). When to use broader internalising and externalising subscales instead of the hypothesised five subscales on the Strengths and Difficulties Questionnaire (SDQ): Data from British parents, teachers and children. Journal of Abnormal Child Psychology, 38(8), 1179-1191. doi:10.1007/s10802-010-9434-x.

Goodman, R. (1997). The Strengths and Difficulties Questionnaire: A research note. Journal of Child Psychology and Psychiatry, 38(5), 581-586. doi:10.1111/j.1469-7610.1997.tb01545.x

Goodman, S. H., Rouse, M. H., Connell, A. M., Broth, M. R., Hall, C. M., \& Heyward, D. (2011). Maternal depression and child psychopathology: A meta-analytic review. Clinical Child and Family Psychology Review, 14, 1-27. doi:10.1007/s10567-010-0080-1 
Hosokawa, R., \& Katsura, T. (2019). Role of parenting style in children's behavioral problems through the transition from preschool to elementary school according to gender in Japan. International Journal of Environmental Research and Public Health, 16(1), 21. doi:10.3390/ijerph16010021

Kuckertz, J. M., Mitchell, C., \& Wiggins, J. L. (2018). Parenting mediates the impact of maternal depression on child internalizing symptoms. Depression \& Anxiety, 35(1), 89-97. doi:10.1002/da.22688

Lopes, C. S., Hellwig, N., Silva, G. A., \& Menezes, P. R. (2016). Inequities in access to depression treatment: Results of the Brazilian National Health Survey - PNS. International Journal for Equity in Health, 15(1), 154. doi:10.1186/s12939-016-0446-1

Marôco,J.(2014).Análisedeequaçõesestruturais:Fundamentos teóricos, software \& aplicações [Structural equations analysis: Theoretical foundations, software \& application]. Pêro Pinheiro, Portugal: Report Number.

Muniz, M., Gomes, C. M. A., \& Pasian, S. R. (2016). Factor structure of Raven's Coloured Progressive Matrices. Psico-USF, 21(2), 259-272. doi:10.1590/141382712016210204

Nantel-Vivier, A., Pihl, R. O., Côté, S., \& Tremblay, R. E. (2014). Developmental association of prosocial behaviour with aggression, anxiety and depression from infancy to preadolescence. Journal of Child Psychology and Psychiatry, and Allied Disciplines, 55(10), 1135-1144. doi:10.1111/jcpp. 12235

Orth, U. (2018). The family environment in early childhood has a long-term effect on self-esteem: A longitudinal study from birth to age 27 years. Journal of Personality and Social Psychology, 114(4), 637-655. doi:10.1037/pspp0000143

Papalia, D. E., \& Feldman, R. D. (2013). Desenvolvimento humano [Human development] (C. Monteiro \& M. C. Silva, Trans., 12nd ed.). Porto Alegre, RS: Artmed.

Schiavo, R. A., \& Perosa, G. B. (2020). Child development, maternal depression and associated factors: A longitudinal study. Paidéia (Ribeirão Preto), 30, e3012. doi:10.1590/1982-4327e3012

Shaw, D. S., Sitnick, S. L., Reuben, J., Dishion, T. J., \& Wilson, M. N. (2016). Transactional effects among maternal depression, neighborhood deprivation, and child conduct problems from early childhood through adolescence: A tale of two low-income samples. Development and Psychopathology, 28(3), 819-836. doi:10.1017/S095457941600033X

Vafaeenejad, Z., Elyasi, F., Moosazadeh, M., \& Shahhosseini, Z. (2018). Psychological factors contributing to parenting styles: A systematic review. F1000Research, 7, 906. doi:10.12688/f1000research.14978.2

Wang, Y. (2018). Intergenerational transmission of depressive symptoms: The role of parental negative perceptions and behaviors. Child Psychiatry \& Human Development, 49(1), 123-136. doi:10.1007/s10578-017-0734-z
Woerner, W., Fleitlich-Bilyk, B., Martinussen, R., Fletcher, J., Cucchiaro, G., Dalgalarrondo, P., ... Tannock, R. (2004). The Strengths and Difficulties Questionnaire overseas: Evaluations and applications of the SDQ beyond Europe. European Child \& Adolescent Psychiatry, 13(Suppl. 2), 47-54. doi:10.1007/s00787-004-2008-0

Wolford, S. N., Cooper, A. N., \& McWey, L. M. (2019). Maternal depression, maltreatment history, and child outcomes: The role of harsh parenting. American Journal of Orthopsychiatry, 89(2), 181-191. doi:10.1037/ort0000365

Zubizarreta, A., Calvete, E., \& Hankin, B. L. (2019). Punitive parenting style and psychological problems in childhood: The moderating role of warmth and temperament. Journal of Child and Family Studies, 28(1), 233-244. doi:10.1007/s10826-018-1258-2

Marianna Ramos e Oliveira has a master's degree from Universidade de São Paulo, Ribeirão Preto-SP, Brazil.

Thaysa Brinck Fernandes Silva has a PhD from Universidade de São Paulo, Ribeirão Preto-SP, Brazil.

Fernanda Aguiar Pizeta is a Professor of the Universidade Paulista, Ribeirão Preto-SP, Brazil.

Sonia Regina Loureiro is a Professor of the Universidade de São Paulo, Ribeirão Preto-SP, Brazil.

\section{Authors' Contribution:}

All authors made substantial contributions to the conception and design of this study, to data analysis and interpretation, and to the manuscript revision and approval of the final version. All the authors assume public responsibility for content of the manuscript.

Associate Editor:

Wanderlei Abadio de Oliveira

Received: Jul. 14, 2020

1st Revision: Nov. 02, 2020

2nd Revision: Jan. 11, 2021

3rd Revision: Apr. 19, 2021

4th Revision: Jul. 06, 2021

Approved: Jul. 09, 2021

How to cite this article:

Oliveira, M. R., Silva, T. B. F., Pizeta, F. A., \& Loureiro, S. R. (2021). Maternal depression, parental practices, and child sex: Prediction of children's behavior. Paidéia (Ribeirão Preto), 31, e3133.doi:https://doi.org/10.1590/1982-4327e3133 